\title{
Quality Management and Evaluation of UHV Transformer Based on Cloud Matter Element
}

\author{
Yingcui Chen ${ }^{1}$, and Xinru Yu ${ }^{1 *}$, Wangyuan $\mathrm{Xie}^{1}$, Chao $\mathrm{Wu}^{1}$ \\ ${ }^{1}$ China Electric Power Research Institute, 100192, Xiaoying East Road, Beijing, China
}

\begin{abstract}
As the critical component of power control and transformation in UHV transmission link, the effective management of UHV Transformer's whole life quality cycle is an important guarantee for the safe and stable operation of power grid. In this paper, through the analysis of UHV Transformer quality management mode, on the basis of summarizing the existing management shortcomings, the cloud matterelement model of UHV Transformer quality statistics is constructed. This model realizes the uncertain transformation of qualitative concept and quantitative value through specific algorithm, and uses shorter time and better scheme to deal with the existing or potential quality problems of substation equipment. In this study, the scientific selection of quality statistical model is used to build the quality management system, carry out the operation status evaluation of UHV Transformer, and optimize and improve the quality control process and control measures.
\end{abstract}

\section{Introduction}

The process of UHV transformer quality control is a comprehensive evaluation problem of multi-level index system. By dividing indicators into original information according to specific stages, the accuracy and rationality of evaluation results can be improved. However, due to the influence of test environment, instrument accuracy and expert experience, the test data of different detection methods are random, and there is no unified standard for the classification of quality evaluation grade of substation equipment[1-3]. In the quantitative processing of indicators, we need to rely on the experience of experts, which brings great uncertainty, which increases the difficulty of data collection and processing. Therefore, it is necessary to select appropriate evaluation methods to evaluate the operation status of substation equipment, and reasonably analyse and process all kinds of data and uncertain information[4].

Because of the characteristics of high voltage and large capacity in UHV project, UHV transformer has special structure compared with conventional transformer. Taking the ODFPS-1000000/1000 UHV transformers as example, which are single-phase-three-winding autotransformer, commonly used in UHV power grid. The following design methods are adopted.

In addition to the structure, compared with conventional transformers, UHV transformers have the following characteristics[5][6]. The design and manufacture of UHV Transformer is difficult, and the external insulation level of the equipment is extremely high. Due to the long span of UHV transmission projects in China, not only the requirements of external insulation, but also the effects of different geographical environment on external insulation should be considered. Because of the large transmission capacity of UHV, unipolar fault or bipolar fault will lead to a serious shortage of power supply capacity of the receiving end system, which will have a huge impact on the power system. If the transmission system cannot bear it, it will directly lead to the collapse of the power grid and cause catastrophic consequences. Therefore, it is necessary to comprehensively consider the impact of the fault on the quality of UHV substation equipment. Electromagnetic phenomena such as radio interference, power frequency electric field and magnetic field produced by high current and high voltage transmission and transformation facilities have a certain impact on the environment. The effective quality management of UHV substation equipment can control the adverse impact on the environment and personnel as much as possible, which is of great significance[7-9].

\section{Comparison and analysis of equipment quality evaluation models}

The process of UHV transformation quality control is a comprehensive evaluation problem of multi-level index system. Dividing the index into stages and improving the original information is conducive to improving the accuracy and rationality of the evaluation results. However, the evaluation process is affected by the test environment, instrument accuracy and expert experience, and the test data of different detection methods are random. There is no unified standard for the classification of quality evaluation grade of substation equipment, and the uncertainty of expert experience in the quantitative

\footnotetext{
*Corresponding author: yuxinru@epri.sgcc.com.cn
} 
processing of qualitative indicators is high, which increases the difficulty of data collection and processing. Therefore, it is necessary to select appropriate evaluation methods to evaluate the operation status of substation equipment, and reasonably analyse and process all kinds of data and uncertain information. Fuzzy reasoning, support vector machine, expert system and other intelligent methods are gradually introduced into the field of electrical equipment evaluation, and their advantages and disadvantages are shown in the table. According to the situation of the equipment, different methods are used to evaluate, which not only makes the complex quality control simple and easy to operate, but also enhances the accuracy of the evaluation results.

Table 1. Comparison and analysis of common evaluation methods

\begin{tabular}{|c|c|c|}
\hline Method & Advantage & Shortage \\
\hline $\begin{array}{l}\text { Fuzzy } \\
\text { inference }\end{array}$ & $\begin{array}{l}\text { Fuzzy diagnosis does } \\
\text { not need to establish } \\
\text { an accurate } \\
\text { mathematical model, } \\
\text { the use of fuzzy } \\
\text { membership function } \\
\text { can achieve } \\
\text { intelligent fuzzy } \\
\text { diagnosis, and can } \\
\text { improve the accuracy } \\
\text { of diagnosis. }\end{array}$ & $\begin{array}{l}\text { For the same } \\
\text { evaluation index, there } \\
\text { may be different } \\
\text { membership functions, } \\
\text { and the evaluation } \\
\text { results are easily } \\
\text { affected by human } \\
\text { subjective factors with } \\
\text { uncertainty. }\end{array}$ \\
\hline $\begin{array}{l}\text { Support } \\
\text { vector } \\
\text { machine } \\
(\mathrm{SVM})\end{array}$ & $\begin{array}{l}\text { This method adopts } \\
\text { the principle of } \\
\text { structural risk } \\
\text { minimization, has } \\
\text { strong generalization } \\
\text { ability, and solves the } \\
\text { problems of small } \\
\text { sample, high } \\
\text { dimension, slow } \\
\text { convergence speed } \\
\text { and local minimum in } \\
\text { practice. }\end{array}$ & $\begin{array}{l}\text { The selection of SVM } \\
\text { kernel function is the } \\
\text { key factor affecting its } \\
\text { performance. } \\
\text { However, there is no } \\
\text { theoretical basis and } \\
\text { effective method for } \\
\text { its selection. Although } \\
\text { SVM has strong } \\
\text { learning ability in a } \\
\text { small number of } \\
\text { samples, its learning } \\
\text { effect is not } \\
\text { significantly improved } \\
\text { with the increase of } \\
\text { the number of } \\
\text { samples. }\end{array}$ \\
\hline $\begin{array}{l}\text { Expert } \\
\text { system }\end{array}$ & $\begin{array}{l}\text { The expert system } \\
\text { can express the } \\
\text { expert knowledge } \\
\text { which cannot be } \\
\text { expressed by } \\
\text { mathematical model } \\
\text { in clear natural } \\
\text { language, which is } \\
\text { easy to understand; } \\
\text { be able to imitate the } \\
\text { work of experts in } \\
\text { specific fields and } \\
\text { deal with very } \\
\text { complex situations, } \\
\text { including abnormal } \\
\text { situations. }\end{array}$ & $\begin{array}{l}\text { When the number of } \\
\text { samples is large and } \\
\text { the spatial distribution } \\
\text { of samples is complex, } \\
\text { the training is difficult } \\
\text { to converge, which } \\
\text { limits the practicability } \\
\text { of the method; there } \\
\text { are some restrictive } \\
\text { factors such as the } \\
\text { bottleneck of } \\
\text { knowledge acquisition, } \\
\text { the vulnerability of } \\
\text { knowledge and the } \\
\text { monotony of } \\
\text { reasoning; and it is } \\
\text { difficult to obtain } \\
\text { knowledge and } \\
\text { express from experts, } \\
\text { with qualitative and }\end{array}$ \\
\hline
\end{tabular}

\begin{tabular}{|c|c|c|}
\hline & & $\begin{array}{l}\text { subjective, difficult to } \\
\text { express quantitatively } \\
\text { and objectively. }\end{array}$ \\
\hline $\begin{array}{c}\text { Bayesian } \\
\text { network }\end{array}$ & $\begin{array}{l}\text { All kinds of Bayesian } \\
\text { classifiers can } \\
\text { adaptively adjust the } \\
\text { network structure and } \\
\text { probability } \\
\text { distribution } \\
\text { parameters to reduce } \\
\text { the impact of } \\
\text { randomness and } \\
\text { fuzziness of state } \\
\text { information on the } \\
\text { results. }\end{array}$ & $\begin{array}{c}\text { It needs a large } \\
\text { number of test } \\
\text { samples, and each } \\
\text { input is required to be } \\
\text { independent. However, } \\
\text { it is limited by the } \\
\text { environment and test } \\
\text { conditions in practical } \\
\text { application, which is } \\
\text { the obvious defect of } \\
\text { various Bayesian } \\
\text { classifier diagnosis } \\
\text { methods. }\end{array}$ \\
\hline
\end{tabular}

\section{QUALITY EVALUATION OF UHV TRANSFORMER BASED ON CLOUD MATTER ELEMENT}

\subsection{Matter element theory}

Matter element is a general term for objects, their characteristics and their values. It links the qualitative and quantitative research of things, so it can fully reflect the relationship between qualitative concepts and quantitative values, and then objectively and accurately describe the change process of things. A matter element with only one feature is usually expressed as follows:

$$
R=(N, c, v)
$$

$\mathrm{N}$ refers to the things studied; $C$ refers to the characteristics of things; $V$ is the quantity value corresponding to the characteristic $\mathrm{C}$ of things. Its $\mathrm{N}$ features can be represented by $\mathrm{n}$ dimensional matter elements, as shown in the formula, which can be expressed as follows:

$$
\left|\begin{array}{ccc}
N & c_{1} & v_{1} \\
& \vdots & \vdots \\
& c_{n} & v_{n}
\end{array}\right|=\left|\begin{array}{c}
R_{1} \\
\vdots \\
R_{n}
\end{array}\right|
$$

$R=\left(N, c_{i}, v_{i}\right)(i=1,2, \ldots n)$, which is called the fractional matter element of R. For the quality control of UHV Transformer, we can use multi-dimensional matterelement model to represent a state of transformer.

\subsection{Cloud model theory}

Cloud is an uncertain transformation model between the qualitative concept of linguistic value description and its numerical representation. The cloud model is based on Gaussian function. Entropy (variance) is used to express the fuzziness of the numerical range of the concept. The numerical feature of super entropy is added to reflect the dispersion of cloud droplets. The cloud model integrates the fuzziness and randomness, and forms the mapping between qualitative and quantitative information, which is the basis of information representation. The most extensive is the normal cloud, and the digital characteristics are shown in the figure below. 
Let $\mathrm{u}$ be a universe expressed by precise numerical value, $\mathrm{u}$ correspond to qualitative concept $A$. for any element $X$ in a universe, there exists a random number y with stable tendency, which belongs to $[0,1]$, which is called the membership degree of $X$ to $A$. then the distribution of membership degree on the universe is called membership cloud, which is called cloud for short. Cloud is composed of many cloud droplets. The overall shape of cloud reflects the important characteristics of qualitative concept, while cloud droplet is the quantitative description of qualitative concept.

Expectation Ex, which represents the expected value of qualitative concept, can be understood as the central value or ideal value, and is essentially the distribution centre of cloud. Entropy En, a measure of uncertainty of qualitative concepts, reflects the acceptable degree of fuzziness in the universe, which is determined by the randomness and fuzziness of concepts. Super entropy he is a measure of entropy uncertainty, which reflects the discrete degree of cloud droplets. It is determined by the fuzziness and randomness of entropy. These three digital features relate the fuzziness and randomness of things, and constitute the uncertain mapping between qualitative concepts and quantitative values.

\subsection{Improved matter element structure of cloud model}

The cloud model is introduced into matter-element structure, and the 'cloud' is used to represent the natural language value of qualitative concept, thus the improved matter-element model based on cloud model is obtained, as shown in the formula:

$$
\left|\begin{array}{ccc}
N & c_{1} & \left(E_{x_{1}}, E_{n_{1}}, H_{e_{1}}\right) \\
\vdots & \vdots & \vdots \\
N & c_{n} & \left(E_{x_{n}}, E_{n_{n}}, H_{e_{n}}\right)
\end{array}\right|=\left|\begin{array}{c}
R_{1} \\
\vdots \\
R_{n}
\end{array}\right|
$$

The three characteristics of expectation, entropy and super entropy can comprehensively consider the randomness and fuzziness of things, so introducing cloud into matter-element theory can solve the problem of uncertainty of things. Accordingly, the correlation function of matter-element analysis based on cloud model has the following three cases.

\section{(1) Correlation function between numerical value and cloud matter element}

The correlation function between the numerical value and the cloud matter element regards the numerical value as a cloud drop, and then the problem is transformed into solving the uncertainty of the cloud drop representing the cloud. Firstly, a normal random number with mean value and standard deviation is generated; then, let the value be $x$, which is called cloud drop; finally, we calculate the correlation degree $k$ that $x$ belongs to this cloud model.

$$
k=\exp \left[-\frac{\left(x-E_{\chi}\right)^{2}}{2\left(E_{n}^{\prime}\right)^{2}}\right]
$$

\section{(2) Correlation function between matter element} and cloud matter element

For the normal cloud, there is the following distribution rule, that is, $99.74 \%$ of the cloud droplets fall between the range of $\left(E_{x}-3 E_{n}^{\prime}, E_{x}+3 E_{n}^{\prime}\right) \cdot\left(E_{x}-3 E_{n}^{\prime}, E_{x}+3 E_{n}^{\prime}\right)$ is regarded as a set, the common and non common parts of two clouds can be represented by $\mathrm{N}$ and $\mathrm{m}$.

$$
K=\frac{|N|}{|M|}
$$

\section{(3) Correlation function between cloud and interval value}

Firstly, the interval values are transformed into clouds, and then the correlation degree between clouds is used to calculate. The interval value is transformed into a cloud, and the index approximation method is used to treat the interval value as a double constrained index $\left[C_{\min }, C_{\max }\right]$. The calculation formula is as follows:

$$
\begin{aligned}
& E_{x}=\frac{C_{\min }+C_{\max }}{2} \\
& E_{n}=\frac{C_{\max }-C_{\min }}{6}
\end{aligned}
$$

\section{(4) Construction of cloud matter element model}

(1) Determine the matter element to be evaluated According to the investigation and analysis and inviting relevant experts to participate in the evaluation, the factors affecting the quality of UHV Transformer can be obtained, as shown in the figure 1.

(2) Determine standard cloud

Considering the development trend of transformer quality control, the state of transformer is divided into five grades: very poor, poor, general, good and excellent, so that the staff can accurately judge the state of transformer.

When building the cloud model, the ratio range is regarded as a double constraint space [Cmin, Cmax]. In order to establish the standard cloud, the interval composed of boundary values of constraint space is extended appropriately, and then Ex and En are obtained by using the transformation relationship between the given interval and cloud model.

(3) Determine the weight of each evaluation index

The improved analytic hierarchy process based on cloud model is used to determine the subjective weight of each index and matter element. For the actual evaluation index, the objective variable weight should be obtained by phase entropy weight method according to its numerical change, and the weight of each index should be obtained comprehensively. In order to determine the weight coefficient $W i$ of the index $C i$, it is necessary to determine the weight $W i$ of each dimension and the weight $W i j$ of each index under each dimension for multi-level evaluation of the quality management system of highvoltage substation equipment.

(4) Determine the correlation between the matter element $P$ to be evaluated and each state level 
Taking the index eigenvalue of the matter element to be evaluated as a cloud droplet, the membership degree of each state level cloud is calculated as follows:

1) A normal random number $E n$ with mean $E n$ and standard deviation $\mathrm{Hn}$ is generated

2) Let this value be $X i$, and $(X i, \mu i)$ is called a cloud drop. $\mu \mathrm{i}$ is the membership degree of $\mathrm{Xi}$ belonging to the cloud, that is, the correlation degree between the object index represented by the value and the object index represented by the cloud.

3) Finally, calculate $\mu i$.

$$
\mu_{i}=e^{-\frac{\left(x_{i}-E_{\chi}\right)^{2}}{2 E_{n i}^{2}}}
$$

(5) Calculate the correlation degree of matter element $p$ to grade state $j$

The matter element to be evaluated can be directly obtained by weighting the membership degree of each state level according to its indexes, and its calculation formula is:

$$
k_{m}\left(p_{m}\right)=\sum_{i=1}^{n} \omega_{i} k_{m j}\left(p_{m}\right)
$$

(6) Grade estimation

According to the principle of maximum membership, the comprehensive grade evaluation is determined. When $p$ belongs to grade $j$ :

$$
k_{j}=\max _{j}(p)
$$

\subsection{Example analysis and model application}

The most direct purpose of determining the matter element to be evaluated for UHV Transformer quality

$$
R_{i j}=\left[\begin{array}{ccc} 
& \text { Worst } & \text { Bad } \\
C_{11} & (30,10,0.7) & (65,1.6667,0.2) \\
C_{12} & (54,14,0.8) & (12.5,0.8333,0.1) \\
C_{21} & (57,14,0.8) & (12.5,0.8333,0.1) \\
C_{22} & (30,10,0.7) & (65,1.6667,0.2) \\
C_{31} & (30,10,0.7) & (65,1.6667,0.2) \\
C_{32} & (30,10,0.7) & (65,1.6667,0.2) \\
C_{33} & (54,15,1) & (8,0.3333,0.04) \\
C_{34} & 0.65,0.1167,0.15) & (0.25,0.0167,0.0025) \\
C_{35} & (54,15,1) & (8,0.3333,0.04) \\
C_{36} & (30,10,0.7) & (65,1.6667,0.2) \\
C_{41} & (30,10,0.7) & (65,1.6667,0.2) \\
C_{42} & (30,10,0.7) & (65,1.6667,0.2) \\
C_{43} & (30,10,0.7) & (65,1.6667,0.2) \\
C_{44} & (30,10,0.7) & (65,1.6667,0.2)
\end{array}\right.
$$

$\begin{array}{cc}\text { Commonly } & \text { Good } \\ (75,1.6667,0.2) & (85,1.6667,0.2) \\ (7.5,0.8333,0.1) & (3.5,0.5,0.065) \\ (7.5,0.8333,0.1) & (3.5,0.5,0.065) \\ (75,1.6667,0.2) & (85,1.6667,0.2) \\ (75,1.6667,0.2) & (85,1.6667,0.2) \\ (75,1.6667,0.2) & (85,1.6667,0.2) \\ (6,0.03333,0.04) & (85,1.6667,0.04) \\ (0.150 .0167,0.0025) & (0.055,0.015,0.0025) \\ (6,0.3333,0.04) & (85,1.6667,0.04) \\ (75,1.6667,0.2) & (85,1.6667,0.2) \\ (75,1.6667,0.2) & (85,1.6667,0.2) \\ (75,1.6667,0.2) & (85,1.6667,0.2) \\ (75,1.6667,0.2) & (85,1.6667,0.2) \\ (75,1.6667,0.2) & (85,1.6667,0.2)\end{array}$

management is to deal with the existing or potential quality problems of substation equipment with the most effective management and control method, the shortest time and the best scheme in each stage. In the practice of substation equipment quality management and control evaluation, according to the investigation and analysis and the invitation of relevant experts, the evaluation values of

\begin{tabular}{|c|c|c|}
\hline $\begin{array}{l}\text { Evaluation } \\
\text { dimension }\end{array}$ & Evaluating indicator & Value \\
\hline \multirow[t]{2}{*}{ Design Stage } & Standard design & 80 \\
\hline & Cost Control & 2 \\
\hline \multirow{2}{*}{$\begin{array}{l}\text { Production } \\
\text { stage }\end{array}$} & Coil Winding control & 5 \\
\hline & Wire control & 70 \\
\hline \multirow{6}{*}{$\begin{array}{l}\text { Operation } \\
\text { stage }\end{array}$} & Overload operation level & 80 \\
\hline & Insulation aging level & 65 \\
\hline & $\begin{array}{l}\text { Short circuit protection } \\
\text { capability }\end{array}$ & 4.8 \\
\hline & $\begin{array}{l}\text { Short circuit protection } \\
\text { capability }\end{array}$ & 0.1 \\
\hline & Wire contact status & 9 \\
\hline & Quality of insulating oil & 80 \\
\hline \multirow{4}{*}{$\begin{array}{l}\text { Installation } \\
\text { stage }\end{array}$} & Installation Preparation & 60 \\
\hline & Operation technology & 85 \\
\hline & Operating conditions & 70 \\
\hline & Installation cycle & 75 \\
\hline
\end{tabular}
each item can be obtained, as shown in table 2 .

Table2. Score table of substation equipment quality control system

The standard cloud model of UHV Transformer quality control evaluation index grade boundary is:

$\left.\begin{array}{c}\text { Best } \\ (95,1.6667,0.2) \\ (1,0.3333,0.04) \\ (1,0.3333,0.04) \\ (95,1.6667,0.2) \\ (95,1.6667,0.2) \\ (95,1.6667,0.2) \\ (1.5,0.5,0.06) \\ 0.005,0.0017,0.0002) \\ (1.5,0.5,0.06) \\ (95,1.6667,0.2) \\ (95,1.6667,0.2) \\ (95,1.6667,0.2) \\ (95,1.6667,0.2) \\ (95,1.6667,0.2)\end{array}\right]$

The correlation degree between the object $\mathrm{P}$ to be evaluated and each evaluation grade index is calculated. The results are as follows

$$
k_{j}\left(v_{j}\right)=\left[\begin{array}{cccccc} 
& \text { Worst } & \text { Bad } & \text { Commonly } & \text { Good } & \text { Best } \\
C_{11} & 0 & 0 & 0.0187 & 0.0100 & 0 \\
C_{12} & 0.0006 & 0 & 0 & 0.0095 & 0.0044 \\
C_{21} & 0.0012 & 0 & 0.0099 & 0.0066 & 0 \\
C_{22} & 0.0005 & 0.0233 & 0.0056 & 0 & 0 \\
C_{31} & 0 & 0 & 0.0057 & 0.0115 & 0 \\
C_{32} & 0.0030 & 1 & 0 & 0 & 0 \\
C_{33} & 0.0041 & 0 & 0.0001 & 0.0377 & 0 \\
C_{34} & 0 & 0 & 0.0090 & 0.0112 & 0 \\
C_{35} & 0.0073 & 0.0081 & 0 & 0 & 0 \\
C_{36} & 0 & 0 & 0.0090 & 0.0112 & 0 \\
C_{41} & 0.0130 & 0.0103 & 0 & 0 & 0 \\
C_{42} & 0 & 0 & 0 & 1 & 0 \\
C_{43} & 0.0002 & 0.0044 & 0.0139 & 0 & 0 \\
C_{44} & 0 & 0 & 1 & 0 & 0
\end{array}\right]
$$

Evaluation results of design stage is: $k_{1 j}\left(p_{1}\right)=$ $(0.0001,0,0.0011,0.0017,0.005)$

According to the principle of maximum subordination, it can be seen that the evaluation of quality control in the design stage is 'Best', and the evaluation result is in the 'Best' level.

Table3. Calculation results of comprehensive correlation degree

\begin{tabular}{|c|c|c|c|c|c|}
\hline Index & Worst & Bad & Commonly & Good & Best \\
\hline C1 & 0.0001 & 0.0000 & 0.00011 & 0.0017 & 0.0005 \\
\hline C 2 & 0.0001 & 0.0020 & 0.0013 & 0.0006 & 0.0000 \\
\hline C3 & 0.0014 & 0.0522 & 0.0074 & 0.0052 & 0.0000 \\
\hline C4 & 0.0004 & 0.0004 & 0.0544 & 0.0290 & 0.0000 \\
\hline C & 0.0020 & 0.0365 & 0.0643 & 0.0547 & 0.0005 \\
\hline
\end{tabular}


It can be seen from table 3 that $k 3=0.0643$, which means that the quality control of substation equipment is at a general level. $k 2=0.0546$, which indicates that the result has a good development trend.

Among them, overload operation is effectively controlled, coil winding control is developing towards a better trend, and low-cost concept is paid more attention to in the design stage of substation equipment. However, the evaluation results of online material control are general, and continue to develop in a poor direction; the aging level of iron core insulation and the contact level of conductor are general; the control level of operation link in substation equipment installation stage is general, and the development trend is worthy of attention.

\section{Conclusion and application}

In this paper, through the analysis of UHV Transformer quality management mode, on the basis of summarizing the existing management shortcomings, the cloud matterelement model of UHV Transformer quality statistics is constructed. The improved cloud matter element model can also be used in transformer fault diagnosis, insulation state assessment of substation equipment, Risk assessment of transformer life cycle cost. The improved cloud matter-element model can also be applied in transformer operation, diagnosis and other fields to solve the problem of state assessment of complex system. The cloud matter-element model is introduced to evaluate the subordinate level of transformer cost risk, and the key risk factors affecting the whole life cycle cost management of transformer are obtained, which can provide reference for the corresponding control strategies for various risk factors in practical application.

\section{Acknowledgments}

The reports research is supported by the 2020 Science and Technology Project of SGCC, 'Research on standardization and technology improvement of $800 \mathrm{kV} 8 \mathrm{GW}$ UHVDC transmission project'(5200202056138A-0-0-00).

\section{References}

1. Lin Yuan. Study on risk assessment model of coal and gas outburst based on cloud matter element model [J]. Modern mining, 2021,37 (03): 234-235 + 241

2. Yu Hongbo, yuan Wanling, Wang Min, Zhang hang, Xiong Wei, yuan Xufeng, Zou Xiaosong. Comprehensive condition evaluation method of power transformer based on asymmetric closeness evidence cloud matter element model [J]. Power grid technology,: 1-9

3. He Guangguang, Xue Xiaolin, Xu Qing, Li Chen, mu huaitao. Calculation of comprehensive efficiency of asset group based on cloud matter element model [a]. Editorial board of China power enterprise management innovation practice (2019). China power enterprise management innovation practice
(2019) [C]. China power enterprise management magazine, 2020:3

4. $\mathrm{Fu}$ Haochuan. Research on transformer fault diagnosis and condition evaluation technology based on DSmT information fusion [D]. North China Electric Power University, 2019

5. Jiang Sijie. Research on typhoon disaster pre assessment of $10 \mathrm{kV}$ distribution lines based on cloud matter element [D]. Fuzhou University, 2018

6. Wang Jianyi, Li Jinzhong, Li Jun, Wu Chao, Zhu Lingyu. Modification method for condition evaluation of main equipment in high altitude DC project $[\mathrm{J}]$. Chinese Journal of electrical engineering, 2016,36 (17): 4786-4793

7. Xu Zhengyu, Li Jinzhong, Wang Ke, Zhao Zhigang, Gao Fei, Li guangfan Partial discharge and breakdown characteristics of oil paper insulation at $40{ }^{\circ} \mathrm{C}[\mathrm{J}]$. Chinese Journal of electrical engineering, 2016,36 (10): 2827-2835

8. $\mathrm{Hu}$ Zibin. Research on transformer insulation condition evaluation based on cloud matter element theory [D]. North China Electric Power University, 2012

9. Xie Qing, Peng Peng, Tangshan, Li Yanqing, Zheng $\mathrm{Na}$, Lu Fangcheng. Research on fault diagnosis method of power transformer based on cloud matter element analysis [J]. High voltage apparatus, 2009,45 (06): 74-77+ 82 